\title{
Research on Optimization of Business Environment in Jilin Province
}

\author{
Yanwei Wang ${ }^{1}$, Yan Zhang ${ }^{2 *}$ \\ ${ }^{1}$ Associate professor of Northeast Electric Power University, research direction innovation and entrepreneurial \\ management \\ ${ }^{2}$ Graduate student of Northeast Electric University, research direction, state-owned enterprise management, innovation \\ and entrepreneurship management \\ ${ }^{*}$ Corresponding author. Email: 359925988@qq.com
}

\begin{abstract}
The business environment of Jilin Province has been continuously improved in recent years, however, Jilin Province compared with the economically developed southeast coastal areas that the rate of improvement is still slower.The economic growth of Jilin Province is slow and the population is lost that reasons include natural factors such as region and climate, as well as social factors such as economic system and concept. We learn from the business environment optimization measures in developed regions and propose government-led measures to optimize the business environment in Jilin Province. Not only can we provide policy ideas for optimizing the business environment in Jilin Province, but also for other provinces in Northeast China and China's less developed provinces that provide reference for business environment optimization.
\end{abstract}

Keywords: business environment, cause analysis, optimization countermeasures

\section{吉林省营商环境优化研究}

\author{
王延伟 ${ }^{1}$ ，张妍 ${ }^{2 *}$
}

\author{
${ }^{1}$ 吉林大学博士后，东北电力大学副教授，研究方向创新与创业管理 \\ 2东北电力大学研究生, 研究方向, 国有企业管理, 创新与创业管理 \\ *通讯作者。电子邮件: 359925988@qq.com
}

\section{摘要}

吉林省营商环境近年来不断改善, 但是与经济发达的东南沿海地区相比, 改善的幅度还较慢, 在经济 新常态的背景下, 整个吉林省在经济发展方面陷入了前所未有的麻烦当中, 经济增长乏力, 人口大量 外流。究其原因, 有地域、气候等自然因素, 也有经济体制、观念等社会因素。借鉴发达地区营商环 境优化措施, 有针对性地提出基于政府主导的吉林省营商环境优化对策, 不仅可以为吉林省营商环境 优化提供政策思路，还可以为东北地区其他省份以及我国经济欠发达省份营商环境优化提供借鉴。

关键词：营商环境，原因分析，优化对策

\section{1. 介绍}

吉林省是地处东北地区中部的内陆省份, 在东北 三省中经济总量最少, 人均收入最低, 高速公路通车 总里程最少。近年来吉林省政府十分重视营商环境构 建, 2016年10月成立了吉林省软环境建设办公室,但 相比其他省市, 发展仍然较慢。所以分析并正视吉林 省营商环境存在的问题, 并探究其原因, 在借鉴国内 外发达国家和地区的经验基础上, 提出吉林省优化营 商环境的对策, 这对吉林省未来经济发展很有禆益。

\section{2.吉林省营商环境有待优化所显现出来的问题}

\section{1. 新常态下的吉林省经济增长率低}

吉林省营商环境有待优化最大的表现就是在经济新常态 的背景下, 吉林省经济增速下降过快, 这是吉林省产业结构 单一, 营商环境有待优化的最大表现。对比吉林省的经济发 展速度与国家整体发展速度，可以发现吉林省经济增速基本 
的黑龙江省，辽宁省以及受到煤炭价格影响巨大的山西省。 2018 年最新的政府工作报告中显示吉林省 GDP 增长率为 $5.3 \%$ [1], 低于全国平均水平 $1.6 \%$ [2]。
接近全国平均水平, 而经济增速的排名在全国大陆地 区 31 个省市排名中十分靠后, 2015 年最低位时全国 排名第 28 名（倒数第四位），仅高于同处东北地区

表 1 2013-16 年吉林省经济增速对比及排名

\begin{tabular}{ccccc}
\hline 年 & 2013 & 2014 & 2015 & 2016 \\
\hline 全国 GDP 增速 $(\%)$ & 7.7 & 7.4 & 6.9 & 6.7 \\
\hline 吉林 GDP 增速 $(\%)$ & 8.3 & 5.8 & 6.5 & 6.9 \\
\hline 吉林省排名 & 26 & 26 & 28 & 25 \\
\hline 数据来原：根据中统计网站数据整理 & &
\end{tabular}

数据来源: 根据中国统计局网站数据整理

\section{2. 研发经费和强度双低}

研发经费和研发强度是可以考察一个地区经济 可持续发展和创新能力的重要指标。吉林省拥有众多 高校, 但是吉林省的研发经费 2013-2016 年平均仅为 132 亿元左右, 与发达省份差距巨大, 2016 年研发投 入最大的广东省研发经费为 2035.1 亿元, 为 2016 年 吉林省研发经费 139.7 的 15 倍左右。不仅如此, 其 研究强度也与经济发达省市差距巨大, 近年来研发强 度仅在 2015 年超过 $1 \%$, 为 $1.01 \%$, 不及全国平均研 发强度水平的一半。2013-2015 年在我国大陆 31 个省 市排名第 22 位, 且在 2016 年下滑到第 24 位。北京 市研发强度达到了 $5.96 \%$, 是吉林省的 6 倍。上海 （3.82）、天津（3.00）、江苏（2.66）、广东（2.56） 均超过 $2.5 \%$, 与发达国家水平相当或者超过发达国 家的平均水平。另外吉林省基础设施薄弱, 以高速公 路为例, 吉林省高速公路通车里程数在全国排名 23 位（2016 年）, 高速公路密度为 218.41 公路/平方公 里, 全国排名 24 位（2016 年）, 截至 2017 年底, 还有 10 个县级城市没有通高速。在 2012 年全国大型 企业总部所在地排名统计中, 广东省以 174 家排名第 一, 浙江省排名第二, 有 141 家, 吉林省只有 4 家, 并列中国大陆地区 23 位。吉林省修正药业的董事长 修涞贵作为吉林省首富在中国福布斯富豪排行榜中 仅仅并列排名 344 位。也是唯一一位进入中国富豪榜 400 强的吉林富豪。2017 年全年合计有 436 家企业完 成 A 股 IPO (首次公开募股) 上市, 而吉林省仅有一 家。还有一家吉林省企业因为连续三年亏损而被证监 会暂停上市。实际上 2017 年吉林省上市企业没有增 加。2016 年 10 月 18 日, 中共国务院召开振兴东北 经济会议, 李克强讲话中公开了东北经济目前存在两 大危机：从外部来说, 没人愿意投资东北; 从内部来 看, 东北的企业停止发展, 消极度寒冬。另外由于吉 林省人口密度小以及气候原因, 共享单车和滴滴快车 等在经济发达地区盛行的商业形式没有发展起来。

\section{3.吉林省营商环境有待优化的原因}

\section{1 客观气候和地理原因}

吉林省位于中纬度欧亚大陆的东侧, 属于温带大陆性季 风气候, 冬季寒冷漫长。每年的 11 月 15 日至次年 3 月 15 日 无法进行建筑施工, 这严重影响了工程施工速度, 吉林省的 高速公路建设等工程施工速度慢, 而且由于冬季冻土等问题 造成公路施工难度增大, 施工成本增加, 尤其是吉林省的东 部山区, 这造成了吉林省高速公路通车里程和密度在全国排 在比较靠后的位置。由于漫长的冬季每年企业和居民需要缴 纳大量的取暖费（超过 5 个月的供暖期），从而造成企业成 本和人们生活成本的增加。而且由于吉林省冬季干燥寒冷, 心脑血管疾病, 呼吸道疾病等高发。可以说气候条件是吉林 省人才外流的一个很重要的因素。

\section{2 文化方面的因素}

清末民初的闯关东大潮涌入东北大量的山东、河北、河 南、山西、陕西人。这些大量涌入的关里人 (山海关以南) 和关外人 (东北人) 慢慢融合, 逐渐形成了具有东北特色的 东北文化。包括 “闯劲” 没了, 小富即安求安稳、讲义气, 不守规则，人脉文化浓重、官本位思想严重。

\section{3 经济体制方面的因素}

首先是计划经济的余毒, 计划经济造成了官本位的价值 观, 人们在这样的环境中权力寻租, 把权力商品化, 以权力 为资本, 去参与商品交换和市场竞争, 谋取金钱和物质利益。 其次是产业结构单一, 工业结构失衡、企业步履艰难、效益 严重下滑、接续产业贵乏等多重问题, 被称之为 “东北现象”。 同时国有经济比重过高, 吉林省国有经济占比超过 $40 \%$, 远 远高出全国平均水平。最后重引进, 轻服务, 欠缺契约精神, 吉林省的部分地区, 部分官员惰政、吃拿卡要等现象时有发 生。 


\section{4.吉林省营商环境优化对策}

\section{1. 观念上的改变}

首先是创新创业方面观念的改变, 引入新思想、 新模式。举行表彰大会对创业创新先进个人进行表彰 和宣传, 还可以进行吉林企业家评选、宣传、表彰, 激发吉林人骨子中的闯劲。通过软环境办、政协和人 民代表大会等渠道把企业家的心声反映到政府部门。

第二点是政府服务理念上的改变一是向先进地 区对标, 学习香港等我国经济发达地区的 “大市场、 小政府” 方针。另外政府要有长远眼光, 不要竭泽而 渔, 而要 “作大蛋糕, 分大蛋糕” 意识, 从税收等方 面吸引更多的企业到吉林省来创业, 克服官员的政绩 观念和短期思维, 在干部考核时不要仅仅以政绩来说 话, 还要考虑离开后当地的发展问题。

第三点要构建亲清的政商关系, “亲”主要指的 是加强与企业家的联系， “清” 指的是政府在于这些 企业和企业家沟通交往的过程中, 要有边界意识, 规 则意识。

\section{2.加强人才的吸引、培育和素质提升}

首先要留人、育人、吸引人, 一方面通过构建 亲清的政商环境吸引企业入吉, 吸引人才, 另一方面 通过人才政策引进和吸引人才。二是吉林省各地方政 府要将人才政策落实到实处并有相关责任人, 保障人 才引得进、留得住、用得好, 不断增强人才发展竞争 力, 加快推动吉林振兴发展。

第二点要加强政府官员的流动和学习, 利用国家 政策一方面让吉林省公务员到南方发达省份的政府 部门挂职锻炼, 学习南方发达省份在营商环境构建过 程中好的经验以及教训。另外向国家申请让南方发达 地区的干部到吉林省来任职, 将其地区的先进的经验 和理念传授给当地官员。学习他们 “大市场、小政府” 的管理理念, 由及当地民营经济发展的经验。政府公 务人员除了要更新观念与提高服务意识外, 还学要接 受专业知识的学习和培训, 包括现代政务、经济、法 律和信息技术等。

\section{3. 政府的角色定位}

\subsection{1 加强法律环境建设}

完善法律环境是优化营商环境很重要的方面。地 方性政策法规应保持稳定性和连续性, 法律法规的制 定过程应公开透明，营造诚信法治的营商环境[3]。 完善对失信者的惩戒手段, 对破坏营商环境的责任人 要坚决予以查处。财政、税务、工商等部门要加强沟
通，协力构建优良的吉林省营商环境[4]。

\subsection{2 设立半官方半民间机构服务企业}

建立商贸数据库[5], 开展市场推广和各类研讨会。为企 业提供贸易信息服务, 建设区域信息网络，建立信息共享平台 平台包括信息的收集和加工，贸易信息的咨询服务，平台可 以提供免费查询服务，并及时发布其最新的政策以及以后的 发展趋势, 为所有想要投资的企业提供参考, 突破企业和政 府之间的信息壁垒, 减少信息不对称现象 [6],

\subsection{3 设立容错机制为改革者撑腰}

消除干部改革创新、先行先试的 “后顾之忧” ，为敢想 的人 “开绿灯” , 为敢干的人 “息住底” , 只要改革者出于 公心, 经过深入的调查研究, 又经历了必要的程序, 在一定 范围内宽容失败、允许试错, 给改革创新者吃下定心丸。

\section{5.结论}

商业环境的改善是一项系统的长期项目，不可能一蹴而 就。商业环境的改善是一个良性循环。商业环境的改善将 提高企业的数量和质量。企业数量和质量的提高将导致政府 增加税收。实施更多措施以优化业务环境。政府应在优化 商业环境中发挥领导作用。

\section{致谢}

这项工作得到了吉林省社会科学基金吉林省商业 环境优化研究（2018M11）的支持。

\section{REFERENCES}

[1] Zou Naishuo, Shi Lei. The opening of the 13th National People's Congress [N]. Jilin Daily. 2018-01-27, first edition

[2] National Bureau of Statistics. 2017 National Economic and Social Development Bulletin of the People's Republic of China

[3] Li Yicong, Zhang Deyou. The Practice and Enlightenment of the HKSAR Government in Optimizing the Business Environment $[\mathrm{J}]$. The Party School of CPC Qingdao Municipal Committee. Journal of Qingdao Administration Institute, 2013, (02): 50-54

[4] Li Xin. Suggestions for Optimizing the Business Environment in Liaoning Province [J]. China Market, 2018 (2): $30-31$

[5] Liu Yihui. Thinking on the Countermeasures to Optimize 
the Business Environment of Shenyang City [J]. Shanxi Agricultural Economics, 2017, (12): 75

[6]Jin Yanhai. Problems and Countermeasures in Liaoning Business Environment [J]. Journal of Liaoning Institute of Socialism, 2017 (1): 65-67 